\title{
Pre-treatment Strategies for Value Addition in Poultry Litter
}

\section{Taís Carla Gaspareto ${ }^{1}$, Thamarys Scapini ${ }^{1}$, Bruno Venturin ${ }^{2}$, Deisi Cristina Tápparo ${ }^{2}$, Aline Frumi Camargo ${ }^{1}$, Marco Di Luccio ${ }^{3}$, Alexsandra Valerio ${ }^{3}$, Rafael Favretto ${ }^{4}$, Fabiane Goldschmidt Antes ${ }^{5}$, Ricardo Luís Radis Steinmetz ${ }^{5}$, Helen Treichel ${ }^{1}$ and Airton Kunz ${ }^{1,2,5 *}$}

\begin{abstract}
${ }^{1}$ Laboratory of Microbiology and Bioprocess, Federal University of Fronteira Sul, Erechim, Brazil, ${ }^{2}$ Western Paraná State University, Cascavel, Brazil, ${ }^{3}$ Department of Chemical and Food Engineering, Federal University of Santa Catarina, Florianópolis, Brazil, ${ }^{4}$ Center for Agricultural Sciences, Santa Catarina State University, Lages, Brazil, ${ }^{5}$ Embrapa Suínos e Aves, Concórdia, Brazil
\end{abstract}

We studied different pre-treatments of poultry litter aiming to add economic value to this residue. Strategies were applied to extract ammonium nitrogen with the aim of allowing its further use as fertilizer, and to promote the hydrolysis and solubilization of lignocellulosic components with the aim of facilitating its subsequent conversion to biogas. Ammonia extraction was performed by solubilization in water in a one-step process and by successive extraction steps (3 times $60 \mathrm{~min}$ ). Successive extractions presented greater removal of total ammonia nitrogen than did one-step extraction, solubilizing about $36 \%$ of the ammonia in water. In parallel pre-treatment using ultrasound was performed to increase carbon bioavailability for anaerobic digestion. Using this tool, $24.7 \mathrm{~g} \mathrm{~kg}^{-1}$ of total organic carbon and $13.0 \mathrm{~g} \mathrm{~kg}^{-1}$ of total reducing sugars were solubilized, employing $10 \%$ dry mass sample amount, $100 \%$ amplitude ultrasound at frequency of $20 \mathrm{kHz}$ amplitude and 2.5 min of treatment (energy input of $299 \pm 7 \mathrm{~kJ} \mathrm{~L}^{-1} ; 3,822 \pm 95 \mathrm{~kJ} \mathrm{~kg}^{-1}$ ). Anaerobic digestion of ultrassound pre-treated biomass was evaluated using a biological biogas production assay, and an increase of $10 \%$ of biogas production was obtained compared to untreated samples (147.9 and $163.0 \mathrm{~mL} \mathrm{~g}^{-1}$ for crude and pre-treated PL, respectively). The findings suggest that these are environmentally friendly and sustainable strategies to add economic value to poultry litter, reducing the environmental impacts of improper disposal.

Keywords: nitrogen recovery, biogas, anaerobic digestion, ultrasound, energy

\section{HIGHLIGHTS}

- Strategies for economic value addition on poultry litter were investigated;

- Successive 3 extractions using water solubilised about $36 \%$ of ammoniacal nitrogen;

- Nitrogen recovery from poultry litter é feasible using water;

- Ultrasound could be employed as pre-treatment strategy to increase biogas production potential.

\section{INTRODUCTION}

The poultry industry has been growing rapidly, spurred by increased consumption of poultry meat and by-products [ABPA (Brazilian Association of Animal Protein), 2018]. Brazil is the secondlargest world producer, producing 13.05 million tons of poultry meat annually [(ABPA (Brazilian Association of Animal Protein), 2018)]. In addition to being a lucrative activity, the poultry industry 

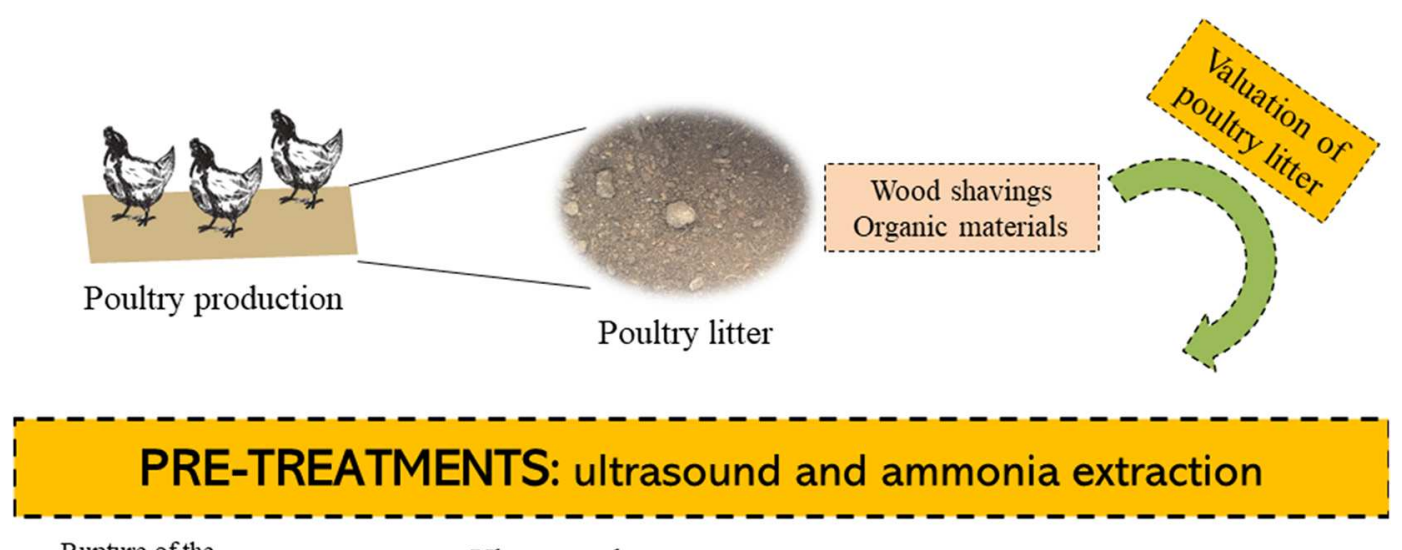

Rupture of the lignocellulosic complex
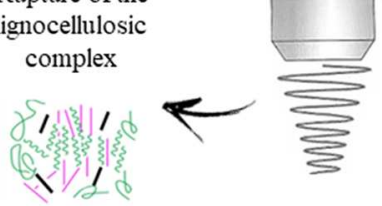

Ultrasound

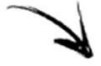

BPP
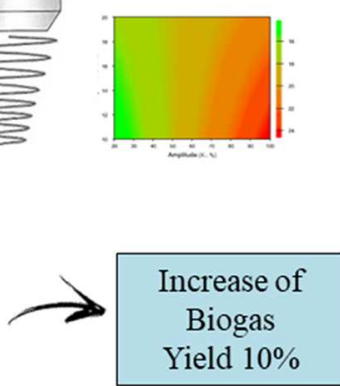

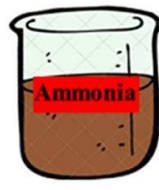

Ammonia extraction
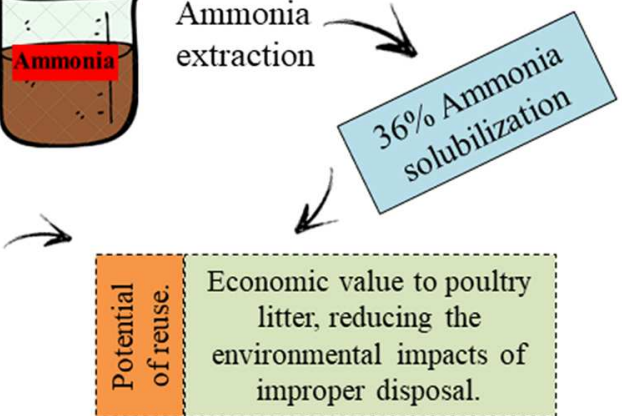

Economic value to poultry litter, reducing the environmental impacts of improper disposal.

Graphical Abstract |

generates large amounts of pollutants (Matusiak et al., 2016), including poultry litter (PL), the primary residue generated in the industry (Burra et al., 2016).

$\mathrm{PL}$ is composed of a mixture of organic matter (i.e., manure, wasted feed, feathers, and skin) and the material that composes the litter (i.e., wood shavings, rice husk, or straw). This material has high biotechnological and economic potential, as in anaerobic digestion (AD) for biogas production (Marchioro et al., 2018; Zahan and Othman, 2019). Energetic conversion of poultry residue is considered a good practice because it reduces pollutant generation and could enhance economical profit of poultry farmers (Marchioro et al., 2018).

Nevertheless, the use of PL in biological processes such as $\mathrm{AD}$ is a major challenge due to the high concentration of total ammonia nitrogen (TAN) and to the complex structure of PL substrate because of the substantial fraction of lignocellulosic material. Intrinsic difficulties of using this substrate in $\mathrm{AD}$ has been recently reviewed by Fuchs et al. (2018). High concentrations of TAN could enhance the concentration of free ammonia (FA) in $\mathrm{AD}$ which is toxic because it damages the structure of microorganisms and causes inhibition of its

Abbreviations: $\mathrm{AD}$, anaerobic digestion; $\mathrm{BPP}$, biogas production potential; $\mathrm{CCD}$, Central composite design; FS, fixed solids; PL, poultry litter; TAN, total ammonia nitrogen; TN, total nitrogen; TOC, total organic carbon; TS, total solids; US, ultrasound; VS, volatile solids; SEM, Scanning electron microscopy. metabolism, compromising their growth (Rajagopal et al., 2013; Tian H. et al., 2018). Several processes have been proposed to minimize FA inhibition, including reduction of ammonia formation precursors or co-digestion with less $\mathrm{N}$-rich materials (Zahan and Othman, 2019), but these approaches could increase the complexity of AD process. Furthermore, the lignocellulosic material in $\mathrm{PL}$, from material that composes the litter, make it recalcitrant to degradation, limiting hydrolysis, and thereby restricting its use in biological processes (Zahan and Othman, 2019). Therefore, to overcome these challenges and increase biogas production from PL, pre-treatment strategies have been used.

Pre-treatment of PL for TAN removal by stripping is reported in some works (Abouelenien et al., 2009; Balaji et al., 2018; Selvaraj et al., 2018). Balaji et al. tested air stripping of ammonia and observed a significant enhance in biochemical biogas potential (BBP) (Balaji et al., 2018). Other simple approach of pretreatment prior to digester unit that could be tested for PL is removal of TAN by water extraction. This procedure has been applied to chicken manure and increased de $\mathrm{C} / \mathrm{N}$ ratio up to 2.7-folds due to ammonia removal (Böjti et al., 2017). The use of stripping or water extraction enables further nitrogen recovery through reaction of ammonia with sulfuric acid solution to produce ammonium sulfate that can be used as nitrogen fertilizer (Sakar et al., 2019; Busato et al., 2020). Therefore, these economically viable and environmentally sustainable removal 
and recovery of nitrogen compound techniques are subjects of considerable investigation.

Processes to increase the biodegradability of lignocellulosic structure of PL, reducing its crystallinity and the amorphous components have also been studied for pretreatment and application in AD (Salehian et al., 2013). Usually, the approaches are based on chemical, thermal or enzymatic methods (Costa et al., 2012; Cavalaglio et al., 2018). Costa et al. (2012) evaluated thermochemical pre-treatment in batch experiments as a strategy to improve BBP in PL. In this work, the solubilization of organic carbon was significantly increased with thermochemical pre-treament but authors described that BBP did not increase accordingly which was attributed to possible production of metabolites that could have caused inhibition on methanogenesis. Additionally, chemical and thermal processes are often less attractive due to the costs involved with chemical products and energy consumption.

Ultrasound (US) has been used to increase solubilization of organic carbon on several substrates for $\mathrm{AD}$ (Fernandes et al., 2009; Zou et al., 2016; Langone et al., 2018). Is consists of a mechanical process where acoustic waves in frequency of $20 \mathrm{kHz}$ or higher causes the effect known as cavitation in liquid medium that result in bubble formation and subsequent collapse generating high pressure gradients, thereby increasing reactivity and production of free radicals $(\bullet \mathrm{OH})$ due to homolytical clevage of water molecules (Bremner et al., 2011; Bondhoo and Mohee, 2018). Lignocellulosic biomass transformation was reviewed by Den et al. (2018) and US was classified as a greener process for biomass coversion. According to the authors, ultrasound technologies should replace energy-intensive heating to facilitate efficient chemical reactions. In this sense, US is considered a promising pretreatment technology that could be used without chemical additives or in reduced amounts (Houtmeyers et al., 2014).

Acoustic cavitation facilitates solubilization of organic matter, resulting in larger amounts of substrate readily available for $\mathrm{AD}$, that could accelerate the hydrolysis step and improve final biogas production (Fernandes et al., 2009; Zou et al., 2016). In a comparative study of physical pre-treatment by sludge particle disintegration processes, US demonstrated higher efficiency, increasing the concentration of organic materials and partial deviation of the hydrolytic step in $\mathrm{AD}$ (Houtmeyers et al., 2014). This energy source has already been used to produce furanic platforms from cellulose (Santos et al., 2018). Besides published works using US for lignocellulosic material pre-treatment, no publications were found about its use for PL. therefore, this subject is word of investigation as a promising alternative to establish adequate processes for PL valuation.

The objectives of the present study were (i) to evaluate the extraction of ammonia using water in continuous and successive washing, aiming to reduce the inhibition of subsequent biological processes and the possible recovery of nitrogen from the solution; and (ii) to investigate US pre-treatment of the lignocellulosic complex of PL, aiming to improve the application potential in $\mathrm{AD}$. In the extraction of TAN, the relationship between soluble ammonia concentration and $\mathrm{pH}$ was evaluated. In the US pretreatment, the concentration of total reducing sugars (TRS) and total organic carbon (TOC) were evaluated. Finally, the BBP was studied, as well as the kinetic parameters defined by the Gompertz model.

\section{MATERIALS AND METHODS}

\section{PL Sampling}

PL after 12 production cycles (number of poultry feedlots that where housed using the same litter) and wood shavings were collected at a farm localized in Jaborá, Santa Catarina, Brazil. Wood shaving is the started material used to prepare the poultry house, while PL was collected after its removal from the poultry house. The samples were homogenized and divided in subsamples using a quarter (model H-3980, Humboldt). After were stored in a vaccum bag at $-20^{\circ} \mathrm{C}$.

\section{Chemical Characterization of Samples and Analytical Approaches}

PL samples were analyzed for determination of total solids (TS), fixed solids (FS), volatile solids (VS), total nitrogen (TN), TAN, phosphorous, potassium, and total carbon (TC), following the Standard Methods for Analysis of Water and Wastewater (APHA AWWA WEF, 2012). TC and TN were determined using an elemental analyzer CHNS-O Flash 2000 (Thermo Scientific) following the manufacturer recommendations.

TAN determination in liquid samples was performed using the colorimetric method in a flow injection analysis system (model 2500, Fialab Instruments, Seattle, USA) using methods adapted from APHA AWWA WEF (2012). TOC was determined in liquid fractions using a TOC analyzer (TOC-LCPH/CPN, Shimadzu, Kyoto, Japan) following the manufacturer recommendations. TRS was determined using the dinitrosalicylic acid (DNS) method and evaluated on a UV-VIS spectrophotometer (model UV-M51, Bel Engineering, Italy) at $540 \mathrm{~nm}$, according to Miller (1959). All analytical parameters were quantified according to standard Methods (APHA AWWA WEF, 2012) and analyses were performed in triplicate following standardized protocols based on good laboratory practices and quality assurance policy.

The results of chemical characterization is expressed as relation of analyte mass in base of natural sample mass. For example, TAN results is expressed as $\mathrm{g} \mathrm{kg}^{-1}$ and represent mass of nitrogen (as N-NH3) based natural PL mass.

\section{Evaluation of the Ammonia Solubilization in Water}

TAN solubilization experiments were conducted in two experimental ways. In the first way, one step solubilization process was used: $50 \mathrm{~g}$ of samples were added to $500 \mathrm{~mL}$ of distilled water and maintained under agitation at $130 \mathrm{rpm}$ in JarTest system (model JT102, Milan). The experiment lasted $180 \mathrm{~min}$ and samples were collected, placed on filter paper and analyzed for TAN. The $\mathrm{pH}$ of suspension was continuously measured using a portable probe (Hanna, model HI 8424).

The second way was a successive solubilization process, where $50 \mathrm{~g}$ of samples where placed in a glass becker and $167 \mathrm{~mL}$ of 
distilled water were added then kept under agitation at 130 $\mathrm{rpm}$. The agitation was stopped after $60 \mathrm{~min}$ for decantation and separation of liquid and solid fractions, and the solid was submerged again in $167 \mathrm{~mL}$ of distilled water and maintained under agitation for $60 \mathrm{~min}$. The procedure was performed three consecutive times and the liquid fraction was sampled for TAN and TOC determination in all collected supernatant samples.

\section{Evaluation of Increase in PL Lignocellulosic Fraction Bioavailability PL Pre-treatment Using US}

PL pre-treatment using US was performed using an ultrasonic processor from Qsonica (Newtown, USA) operating with an output frequency of $20 \mathrm{kHz}$ and equipped with a titanium probe with a tip of $12-\mathrm{mm}$ diameter. The maximum output power of the equipment was $700 \mathrm{~W}$. The absolute energy delivered to the samples is shown on the equipment display, in Joules (J). The energy density $\left(\mathrm{kJ} \mathrm{L}^{-1}\right)$ was determined as the absolute energy divided by the volume of the sample treated $(40 \mathrm{~mL})$ (Mason et al., 2011).

The experimental design methodology was used to evaluate the effect of US pre-treatment on PL, aiming to evaluate the possibility of increasing the availability of lignocellulosic fraction of biomass. Central composite design (CCD) $2^{2}$ was developed according to the methodology proposed by (Rodrigues and Iemma, 2014), using a $2^{\mathrm{k}}$ complete factorial scheme, where " $\mathrm{k}$ " is the number of independent variables under study, and the assays (factorial points " $K$ ") were determinate by the exponential expression $\left(2^{\mathrm{k}}=\right.$ " $\mathrm{K}$ ”).

In this study, the experimental design was used to evaluate the dry mass (10 to 20\%) and US amplitude (20 to 100\%), resulting in a CCD $2^{2}$ with four assays (levels $-1 ;+1$ ), and three central points (level 0 ) to evidence the reproducibility of the process and possible to determine the standard error. The dependent variables evaluated were TOC and TRS. The samples were exposed to US for $2.5 \mathrm{~min}$. For the experiments, 4, 6, and $8 \mathrm{~g}$ of PL (corresponding to 10,15 , and $20 \%$ of solids, w) were transferred to a $100 \mathrm{~mL}$ glass becker and $40 \mathrm{~mL}$ of deionised water was added.

After US pre-treatment, the samples were centrifuged (model Universal 320, Hettich) at 3,500 rpm, $5 \mathrm{~min}$, and the supernatant was used for the determination of TRS and TOC. A solid fraction obtained after US pre-treatment was dried in an oven at $105^{\circ} \mathrm{C}$ and analyzed using scanning electron microscopy (SEM) on Hitachi equipment (model TM3030). SEM analyze was performed in a scanning electron microscope (SEM/EDX, TM3030, Hitachi) in samples: crude PL (control) and the CCD $2^{2}$. Samples were fixed with carbon tape on aluminum holders and then coated by 18 gold sputtering (Ernest Fullam) for 30 s. All SEM analysis were carried out at $15-19 \mathrm{kV}$.

\section{Increased Energy Applied to PL}

Assays of increasing the exposure time of the samples to US were performed, aiming to increase the energy applied in the PL and enabling greater degradation of the lignocellulosic structure. The conditions pre-established by CCD $2^{2}$ were used for assays, with $3.4 \mathrm{~g}$ (dry mass) of samples in $27 \mathrm{~mL}$ of distilled water and US at $100 \%$ amplitude. The exposure times varied from 5 to $20 \mathrm{~min}$. The assays were conducted in triplicate and the responses were expressed as TRS and TOC.

\section{Biochemical Biogas and Methane Potential Assay}

The biochemical biogas potential (BBP), in batch tests, were used to evaluate the PL biogas recovery and pretreatments efficiency on the kinetic parameters. The bioassays were performed according (VDI 4630, 2016) using $250 \mathrm{~mL}$ glass digester coupled to gruaduated $500 \mathrm{~mL}$ eudiometer tube.

Reactors were filled with $200 \mathrm{~g}$ of previously acclimated mesophilic inoculum and mixed with $4 \mathrm{~g}$ of substrate of crude PL or 4,6 , or $8 \mathrm{~g}$ of PL after US pre-treatment (as described before). The proportion of substrate/inoculum was performed according to the guideline VDI $4630\left(\mathrm{VS}_{\text {substrate }} / \mathrm{VS}_{\text {inoculum }} \leqslant\right.$ 0.5). After the reactor was coupled to the eudiometer tube, sealed and the headspace flushed using $\mathrm{N}_{2}$. The reactor was kept at $37^{\circ} \mathrm{C}$ in a thermostatic bath. The biogas production was measured daily by sealing liquid level displacement (sealing solution according, DIN Deutsches Institut für Normung., 1985) until stability ( $\mathrm{dV} / \mathrm{dt}<1 \%$ of cumulative volume), usually for 30 days. Assays were performed in triplicate. At the same time control tests are carried out to evaluate the biogas production from the inoculum, as negative control (blank), and a second with high purity microcristalline cellulose (Type 20, Sigma-Aldrich) as positive control substrate. The data analysis and quality control were performed as recommended as suggested by Holliger et al. (2016). The $\mathrm{CH}_{4}$ content in biogas was determined by infrared absorption sensors using BIOGAS 5000 (Landtec, USA).

The enrichment and acclimated mesophilic inoculum was obtained from a lab scale bioreactor described by Steinmetz et al. (2016). It consisted of equal parts of dairy manure mixed with UASB sludge from an industrial food wastewater treatment plant and mixed with UASB sludge from swine manure wastewater treatment plant. The inoculum reactor was maintained under mesophilic conditions $\left(37 \pm 1^{\circ} \mathrm{C}\right)$ and previously feed with PL for acclimation. Seven days prior to the start of the experiments, feeding of inoculum was interrupted to reduce the baseline effect (Steinmetz et al., 2016).

\section{Gompertz Model}

The Gompertz model (Equation 1) was applied to determine the kinetic parameters of substrate degradation for biogas production (Ware and Power, 2017).

$$
M(t)=A * \exp \left(-\exp \left(\left(\frac{\mathbf{r}_{\mathbf{m}}}{\mathbf{A}}\right) *(\lambda-\mathbf{t}) * \mathbf{e} \mathbf{1}+\mathbf{1}\right)\right)
$$

where " $M(t)$ " is cumulative biogas production $\left(m L \mathrm{~g}^{-1}\right)$, in time $\mathrm{t}(\mathrm{d})$, " $\mathrm{A}$ " is the ultimate biogas production $\left(\mathrm{mL} \mathrm{g} \mathrm{g}^{-1} \mathrm{~d}^{-1}\right)$, " $\mathrm{r}_{\mathrm{m}}$ " is the maximal biogas rate $\left(\mathrm{mL} \mathrm{g} \mathrm{g}^{-1} \mathrm{~d}^{-1}\right)$, and " $\lambda$ " is lag phase in days (d). The comparison of parameters of the nonlinear regression model was developed using software Statistic 8 (trial version). 
TABLE 1 | Chemical composition of PL used in pre-treatment experiments (concentrations are mean \pm standard deviation, $n=3$ ).

\begin{tabular}{ll}
\hline Parameter & Concentration \\
\hline TS $\left(\mathrm{g} \mathrm{kg}^{-1}\right)$ & $781.9 \pm 15.2$ \\
FS $\left(\mathrm{g} \mathrm{kg}^{-1}\right)$ & $407.1 \pm 11.0$ \\
VS $\left(\%, \mathrm{~m} \mathrm{~m}^{-1}\right)$ & $374.8 \pm 9.2$ \\
TC $\left(\mathrm{g} \mathrm{kg}^{-1}\right)$ & $170.3 \pm 2.1$ \\
TN $\left(\mathrm{g} \mathrm{kg}^{-1}\right)$ & $22.0 \pm 0.5$ \\
C:N & $7.7: 1$ \\
TAN $\left(\mathrm{g} \mathrm{kg}^{-1}\right)$ & $5.3 \pm 0.2$ \\
Phosphorus $\left(\mathrm{g} \mathrm{kg}^{-1}\right)$ & $12 \pm 0.5$ \\
Potassium $\left(\mathrm{g} \mathrm{kg}^{-1}\right)$ & $24.3 \pm 0.7$ \\
\hline
\end{tabular}

\section{Statistical Analysis}

Statistical analysis of the various responses was performed using the online Protimiza Experimental Design (experimentaldesign.protimiza.com.br). Results were expressed as mean \pm standard deviation. Analysis of variance (ANOVA), effects and means comparison test (Tukey) were performed, and the confidence level used in the experiments was 95\% $(p<0.05)$.

The kinetic parameters data is expressed as normalized volume ( $273 \mathrm{~K}$ and $1,013 \mathrm{hPa}$ ) and based in the VS mass content from the natural substrate.

\section{RESULTS AND DISCUSSION}

\section{Characterization of PL}

Table 1 presents the characterization of PL. The results indicate a C:N ratio of 7.74, considered low for fermentative processes such as $\mathrm{AD}$, and may limit the application of this material (Rajagopal et al., 2013). Furthermore, because it is a material with high content of lignocellulosic compounds, the C:N ratio may not be representative of carbon bioavailability but part of carbon concentration is also from poultry manure. A PL after 12 production cycles was used and therefore this material presents considerable accumulation of manure. However, probably most of the carbon is in the recalcitrant structure that composes the wood shavings and is not available as a substrate for microorganisms. The effective C:N ratio may be lower than the nominal rate, requiring processes to reduce recalcitrant materials (Shen and Zhu, 2018; Chaump et al., 2019). The high TN and TAN present in PL can causes inhibition during AD process. In the $\mathrm{AD}$ hydrolysis step, organic nitrogen is converted to TAN; in alkaline $\mathrm{pH}$ conditions, $\mathrm{FA}\left(\right.$ as $\mathrm{NH}_{3}$ ) is formed. This chemical species can be toxic to microorganisms due to microorganism cell membrane direct permeation (Kunz and Mukhtar, 2016; Tian H. et al., 2018). On the other hand, TN and TAN on PL makes it a compelling source for ammonia recovery for fertilizing or other purposes. Studies have developed proposals to mitigate the harmful effects of high TAN concentrations in PL to enable its application in processes such as AD (Rajagopal et al., 2013; Marchioro et al., 2018). However, in both cases, remains a need for low-cost and simple operation solutions.
The concentrations of phosphorus and potassium were 12.0 and $24.3 \mathrm{~g} \mathrm{~kg}^{-1}$, respectively, characteristic of this kind material and representative of its potential for fertilizing purposes. The concentration of VS was $37.48 \%\left(\mathrm{w} \mathrm{w}^{-1}\right)$ that corresponds to $48 \%$ of TS (dry mass).

\section{Extraction of TAN Using Water}

To develop a simple method that considers the solubility of ammonia in water, the extraction of TAN present in PL was evaluated in two configurations: extraction in one step and successive steps extraction with exchange of aqueous medium.

Figure 1 shows the results of TAN in one-step extraction of PL for $180 \mathrm{~min}$ compared to suspension $\mathrm{pH}$.

TAN extracted from PL into solution reached $1.31 \mathrm{~g} \mathrm{~kg}^{-1}$ after $30 \mathrm{~min}$ of extraction, corresponding to $24.5 \%$ of TAN of PL sample (Table 1). This value remained almost constant up to $180 \mathrm{~min}$ of extraction (solubilization of $26.6 \%$ of ammoniacal nitrogen). The $\mathrm{pH}$ in solution remained close to 9.0, highlighting the alkaline characteristics of PL. The solubilization of ammonia in water was expected because of its solubilization characteristics. This chemical species is highly soluble in water, where at $25^{\circ} \mathrm{C}$ and $1 \mathrm{~atm}$ the solubility of $\mathrm{NH}_{3}$ é $34 \%$, producing an alkaline solution due to chemical equilibrium displacement to $\mathrm{NH}_{3}$ (Félix and Cardoso, 2004; Kunz and Mukhtar, 2016).

The experiment of one-step extraction was maintained up to $70 \mathrm{~h}$ (results not shown); we observed that, after $24 \mathrm{~h}$, the concentration of TAN on solution began to decrease, with the concomitant reduction of $\mathrm{pH}$. This behavior is probably related to $\mathrm{NH}_{3}$ volatilization.

To increase ammoniacal nitrogen solubilization from PL, successive extraction experiments were carried out. Ammoniacal nitrogen concentrations after each extraction were 1.21, 0.42, and $0.27 \mathrm{~g} \mathrm{~kg}^{-1}$, respectively, corresponding to $36 \%$ of TAN in PL (Table 1). Compared to the maximum efficiency of solubilization obtained in one-step experiment (26.6\%), it could be concluded that successive extraction was more effective for TAN solubilization. Böjti et al. (2017) used water extraction for poultry manure pre-treatment and obtained in increase C:N ratio of 2.7-folds and observed a reduction of $\mathrm{TN}$ of 53.75 to $21.99 \mathrm{mg} \mathrm{kg}^{-1}$. In the present work the C:N ratio from 7.7 to 8.5 . However, PL is a more complex substrate than poultry manure due to the presence of lignocellulosic material. Additionally, the concentration of TN in the material used in present work is much higher than in above cited work $\left(22.0 \pm 0.5 \mathrm{~g} \mathrm{~kg}^{-1}\right.$, Table 1$)$.

The results obtained on solubilization experiments suggest that this approach could be an efficient and low-cost tool for PL pre-treatment. The liquid fraction obtained after solubilization, rich in ammoniacal nitrogen (TAN concentration in solution around $400 \mathrm{mgN} \mathrm{L}^{-1}$ ), could be employed for nitrogen recovery for fertilizer or other uses of ammonia rich solutions (Zhang et al., 2020).

Based on this information, a preliminary assay of biogas recovery after PL water extraction was carried out (Supplementary Data). After washing process the BBP of the solid fraction did not change significantly. However, after the washing process, the lag phase was suppressed ( $\lambda$ from 0.5 to $<0.1 \mathrm{~d}$ ), there was observed an increase in the maximum 


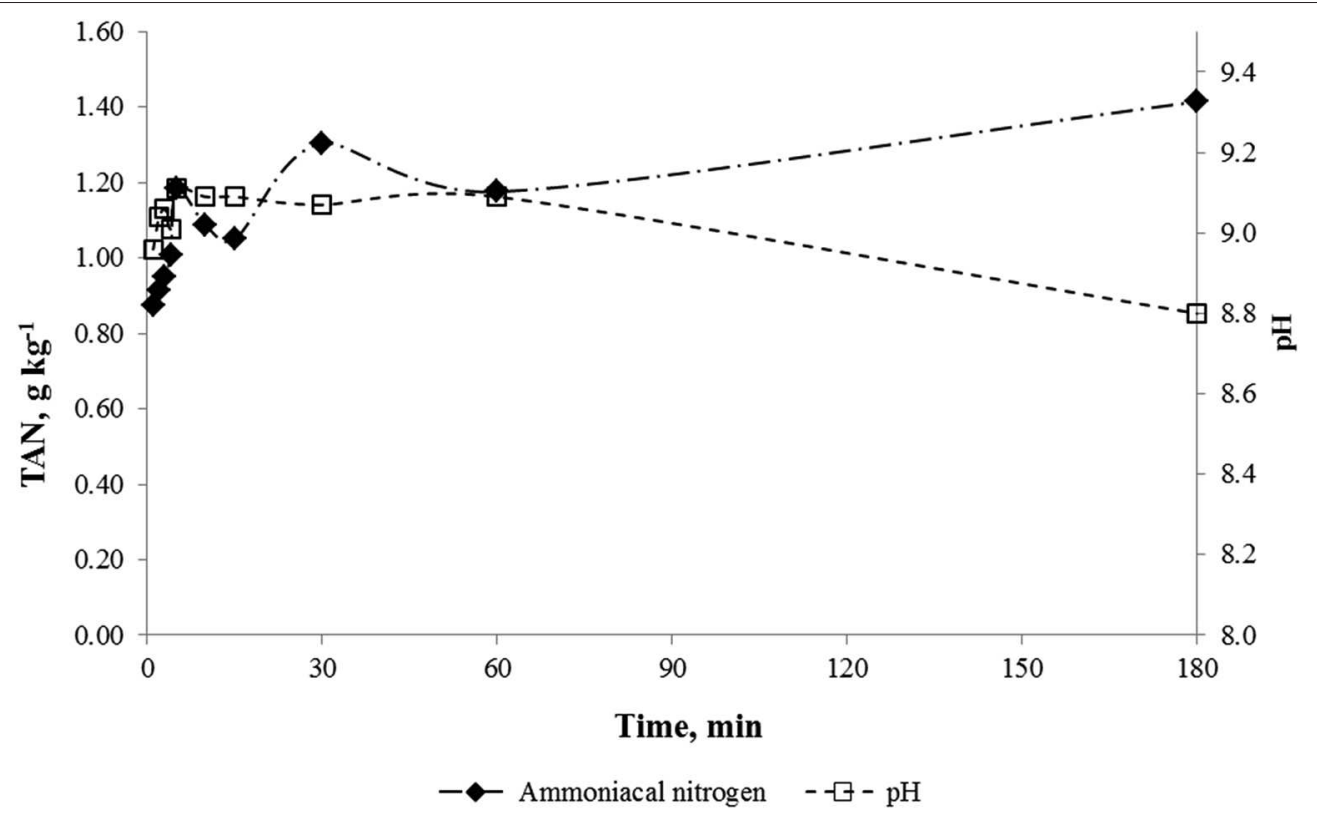

FIGURE 1 | Solubilization of ammoniacal nitrogen from PL in one extraction step experiment. Note: Experimental error for all assays was <5\%.

biogas production rate $\left(\mathrm{r}_{\mathrm{m}}\right.$ from 15.8 to $\left.25.6 \mathrm{~mL} \mathrm{~g}^{-1} \mathrm{~d}^{-1}\right)$ and observed acceleration of the anaerobic digestion process $\left(\mathrm{r}_{\mathrm{m}}\right.$ day occurrence reduce from 3.2 to $1.6 \mathrm{~d}$ ).

\section{US Action on Pre-treatment of PL Lignocellulosic Fraction}

The lignocellulosic structure of PL is difficult to degrade using biological processes, limiting its application to biotechnological processes due to its recalcitrant characteristics (Marchioro et al., 2018). Nevertheless, using pre-treatment of the lignocellulosic structure, it is possible to increase the potential of this biomass for application in fermentative processes (Bondhoo and Mohee, 2018; Den et al., 2018). To determine whether the US effect would be enough to improve the availability of the lignocellulosic structure of the PL, an experimental design was constructed evaluating the influence of the dry mass of the residue on the system and the US amplitude.

Table 2 presents the matrix of experimental design CCD $2^{2}$, where the response variables were TOC solubilization and TRS.

Using statistical analysis with 95\% confidence for the response variables (TOC solubilization and TRS), it was observed that the US amplitude (\%) was the only significant independent variable for increased carbon solubilization after pre-treatment. The TRS concentration was influenced by both response variables. Based on these results, mathematical models (Equations 2 and 3) were proposed to determine TOC (Y1) and TRS (Y2) in the system, being US amplitude $\left(\mathrm{x}_{1}\right)$ and dry mass $\left(\mathrm{x}_{2}\right)$, increasing the possibility of valorization of PL through fermentative processes such as AD.

$$
\begin{gathered}
Y 1=19,08+3,82 x_{1}-0,31 x_{2}-1,44 x_{1} x_{2} \\
Y 2=8,61+2,06 x_{1}-1,16 x_{2}-1,20 x_{1} x_{2}
\end{gathered}
$$

TABLE 2 | CCD $2^{2}$ presented with codified and real values, for poultry litter TOC solubilization and TRS after US pre-treatment.

\begin{tabular}{lcccccc}
\hline Assay & $\begin{array}{c}\text { US } \\
\text { Amplitude } \\
(\%)\end{array}$ & TS (\%) & $\begin{array}{c}\text { TOC } \\
\left(\mathbf{g ~ k g}^{-1} \mathbf{)}\right.\end{array}$ & $\begin{array}{c}\text { TRS } \\
\left(\mathbf{g ~ k g}^{-1} \mathbf{)}\right.\end{array}$ & $\begin{array}{c}\text { Energy } \\
\left(\mathbf{k J ~ L} \mathbf{~}^{-1} \mathbf{)}\right.\end{array}$ & $\begin{array}{c}\text { Energy } \\
\left(\mathbf{k J ~ k g}^{-1} \mathbf{)}\right.\end{array}$ \\
\hline 1 & $-1(20)$ & $-1(10)$ & 14.1 & 6.5 & $85 \pm 1$ & $1090 \pm 4$ \\
2 & $1(100)$ & $-1(10)$ & 24.7 & 13.0 & $299 \pm 7$ & $3822 \pm 95$ \\
3 & $-1(20)$ & $1(20)$ & 16.4 & 6.6 & $79 \pm 1$ & $1012 \pm 16$ \\
4 & $1(100)$ & $1(20)$ & 21.1 & 8.3 & $226 \pm 5$ & $2891 \pm 66$ \\
5 & $0(60)$ & $0(15)$ & 16.9 & 9.4 & $180 \pm 1$ & $2300 \pm 9$ \\
6 & $0(60)$ & $0(15)$ & 20.4 & 8.2 & $181 \pm 3$ & $2312 \pm 34$ \\
7 & $0(60)$ & $0(15)$ & 19.9 & 8.2 & $180 \pm 2$ & $2301 \pm 30$ \\
\hline
\end{tabular}

Contour curves (Figure 2) were generated after validation ( $p$ $<0.05$ ) of a mathematical model for the analysis of variance (ANOVA), with a determination coefficient $\left(R^{2}\right)$ of $90.3 \%$ for TOC and $96.6 \%$ for TRS. When evaluating the contour curves, it was observed that, regardless of the amount of dry matter, the TOC solubilization increased with increasing US amplitude. A similar phenomenon was observed for TRS, where higher US amplitudes and lower dry mass resulted on the highest yields. The optimal region determination was with maximum amplitude (100\%) and the lower amount of dry matter (10\%), where TRS and TOC obtained were 13.0 and $24.7 \mathrm{~g} \mathrm{~kg}^{-1}$, respectively. US amplitude is related to energy applied to the reaction system. Therefore, it was observed that the application of more energy was favorable to increase soluble organic carbon levels.

In the biogas production, the presence of higher bioavailable carbon concentration facilitates the transfer of electrons between 

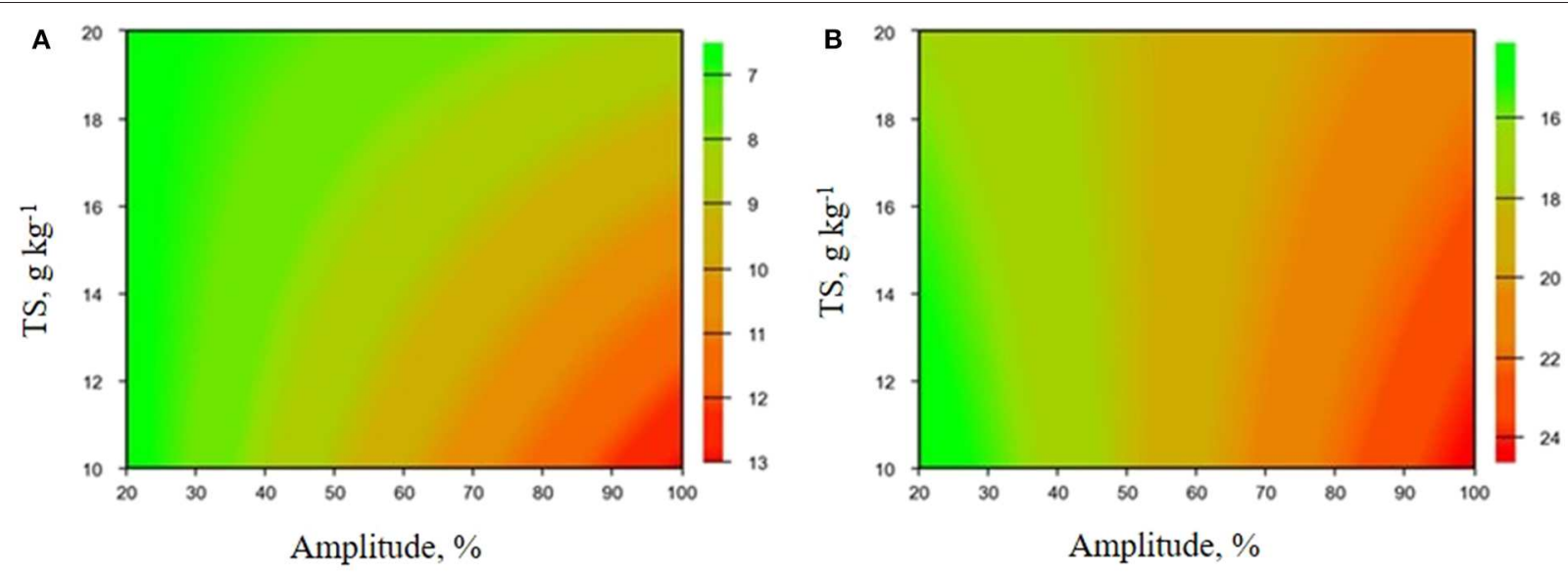

FIGURE 2 | Influence of TS and US amplitude on (A) TRS concentration and (B) TOC solubilization in PL pre-treatment.

TABLE 3 | TOC and TRS results for increased energy applied to PL by increasing US exposure time.

\begin{tabular}{|c|c|c|c|c|c|}
\hline Assay & $\begin{array}{l}\text { Time } \\
\text { (min) }\end{array}$ & $\begin{array}{c}\text { TOC } \\
\left(g_{\left.k g^{-1}\right)}\right.\end{array}$ & $\begin{array}{c}\text { TRS } \\
\left(\mathrm{g} \mathrm{kg}^{-1}\right)\end{array}$ & $\begin{array}{l}\text { Energy } \\
\left(\mathbf{k J} \mathbf{L}^{-1}\right)\end{array}$ & $\begin{array}{c}\text { Energy } \\
\left(\mathbf{k J ~ k g}^{-1}\right)\end{array}$ \\
\hline U1 & 5 & $34.4^{a} \pm 0.4$ & $16.5^{\mathrm{a}} \pm 2.1$ & $819^{a} \pm 25$ & $1044^{a} \pm 306$ \\
\hline U2 & 10 & $36.5^{a, b} \pm 4.9$ & $15.0^{\mathrm{a}} \pm 5.7$ & $1671^{b} \pm 71$ & $21307^{b} \pm 962$ \\
\hline U3 & 15 & $40.5^{b, c} \pm 3.7$ & $13.0^{\mathrm{a}} \pm 1.4$ & $2299^{c} \pm 119$ & $29355^{c} \pm 1471$ \\
\hline U4 & 20 & $45.4^{c} \pm 1.2$ & $17.0^{\mathrm{a}} \pm 1.4$ & $3268^{d} \pm 48$ & $41647^{d} \pm 683$ \\
\hline
\end{tabular}

Equal lowercase letters in same column do not differ statistically from each other by Tukey test (95\% confidence level).

fermenting bacteria and methanogenic archaea, accelerating the assimilation of acetate by acetoclastic methanogens that are the predominant microorganisms in $\mathrm{AD}$ and are responsible for producing 60 to $70 \%$ of methane (Biton, 2010; Yun et al., 2018).

Increased TRS concentration may result from the destruction of the lignin-carbohydrate complex, causing the release of sugars from the biomass structure. US pre-treatment may increase the accessibility of microorganisms and enzymes to structures with easy biological degradation, and this result becomes relevant for application in fermentative processes and may be indicative of improvement in hydrolysis steps and reaction rate of these substrates (Shen et al., 2018).

The US pre-treatment on assay 2 resulted in TOC of $24.7 \pm$ $0.7 \mathrm{~g} \mathrm{~kg}^{-1}$ and corresponds to $14.5 \%$ of total carbon present in raw PL $\left(170.3 \mathrm{~g} \mathrm{~kg}^{-1}\right)$. TOC in supernatant obtained in water extraction experiments was $16.5 \pm 0.5 \mathrm{~g} \mathrm{~kg}^{-1}$ which about $33 \%$ lower than TOC solubilised by US. The increase in US energy applied has been related to increase in bioavailable TOC of biomass (Garoma and Pappaterra, 2018). The US energy applied in assay 2 was $299 \pm 7 \mathrm{~kJ} \mathrm{~L}^{-1}$, similar to previously reported values (Pérez-Elvira et al., 2014).

The higher energy applied to the system by the increase of US amplitude increased the concentrations of TOC. Assuming that the increases of TOC and TRS are partially related to the degradation of the lignocellulosic complex of the PL (considering that feces and other no lignocellulosic components of PL are easier to solubilise), it can be inferred that the increase of energy applied to the system would cause an even greater degradation of this fraction. Therefore, experiments were carried out to increase the amount of energy applied to the system by applying US for longer times. The results are presented in Table 3.

The sample pre-treated for $20 \mathrm{~min}$ (U4) expressed the highest TOC concentration (45.4 $\left.\mathrm{g} \mathrm{kg}^{-1}\right)$. The effectiveness of US on organic compounds solubilisation was verified compared to crude sample. The longer US application time (higher energy applied) results in a higher TRS solubilisation.

\section{Scanning Electron Microscopy}

Alterations in PL structure were evaluated using SEM images of the untreated substrate and assays of US pre-treatment of CCD $2^{2}$ (Figure 3).

SEM showed that the structure of the PL changed after US pre-treatment, showing regions with greater disintegration and smaller particles, compared to the crude material. It is interesting to note the heterogeneous surface with particles of various sizes on samples after US treatment.

The sample of crude PL had less rough surface than all other conditions studied, maintaining its preserved surface structure. In all pre-treated samples, it was observed greater distribution and increase of surface roughness compared to control. This observation was also reported in the study of Zou et al. (2016). This change in physical structure may be linked to the effect of US cavitation that acts on the sample via shear forces (Lippert et al., 2018). Mason et al. (2011) found that the collapse of cavitation bubbles in water and near solid materials can lead to changes in the surface, resulting in erosion and abrasion.

SEM results corroborated the results of TRS and TOC release assays, and those results presented by Zou et al. (2016). These authors studied the effect of US pre-treatment on corn straw and bovine manure and reported that sonication reduced particle 

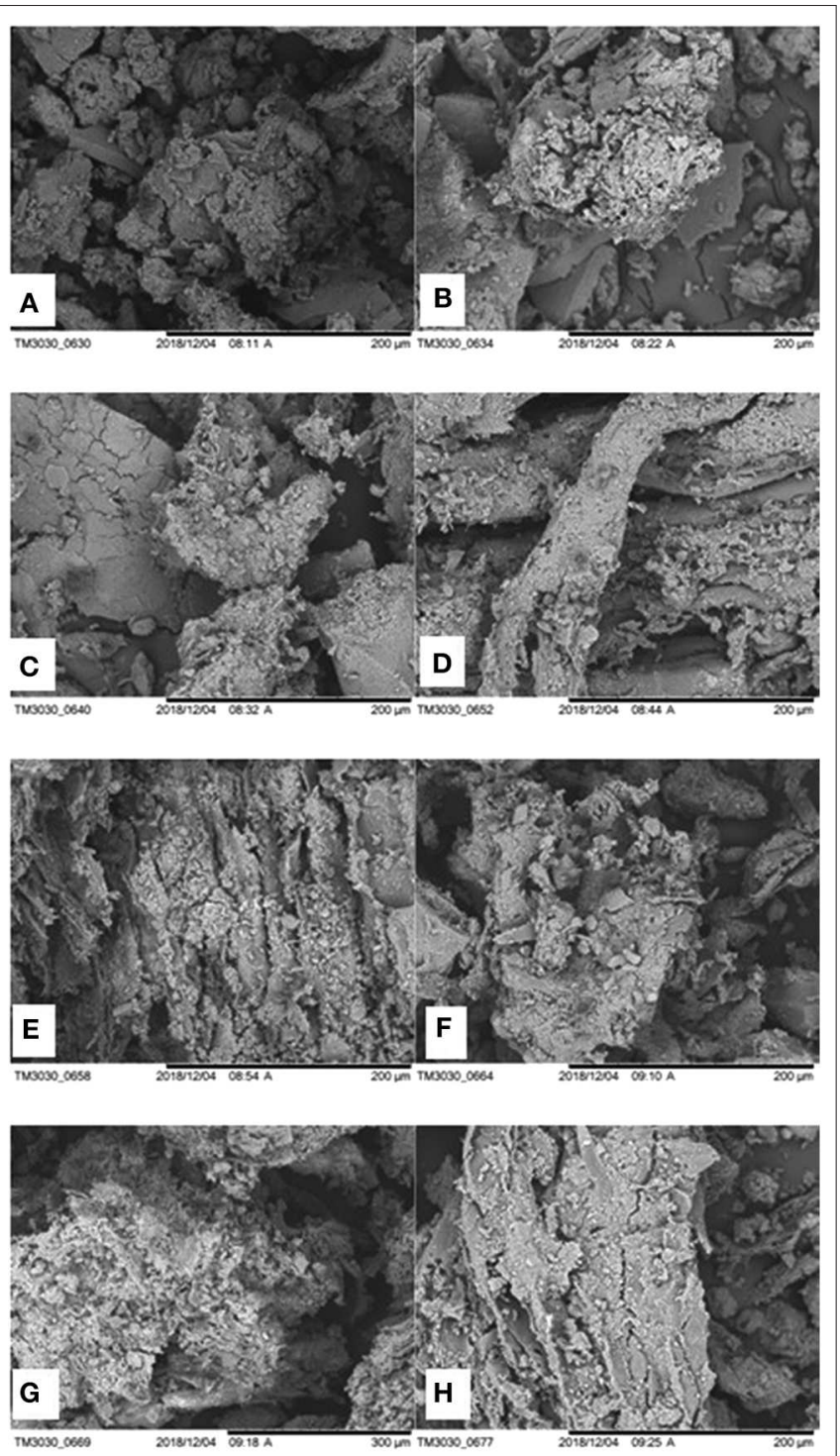

FIGURE 3 | SEM images of crude PL and assays after US pre-treatment. Where: (A) crude PL; (B) Assay 1; (C) Assay 2; (D) Assay 3; (E) Assay 4; (F) Assay 5; (G) Assay 6; (H) Assay 7.

diameter and increased corn straw roughness, in addition to making the surface of bovine manure more distributed.

\section{BBP of PL After US Pre-treatment}

$\mathrm{BBP}$ was performed to determine changes in biogas production in the PL sample after US pre-treatment. Samples of CCD $2^{2}$ and US energy amplification assays were used in this study.

Based on the cumulative biogas production from the BBP assays performed, the kinetic parameters (ultimate biogas production potential, maximum velocity of biogas production, and day of occurrence of the maximum velocity of biogas production and duration of lag phase) were calculated using the modified Gompertz model. The results are presented in Table 4.
The maximum $\mathrm{BBP}$ for crude $\mathrm{PL}$ (without pre-treatment) was $147.9 \mathrm{~mL} \mathrm{~g}^{-1}$ and a biochemical methane production (BMP) of $81.8 \mathrm{~mL} \mathrm{~g}^{-1}\left(\mathrm{CH}_{4} 55.3 \%\right)$. The BMP in PL is very variable and depends on the animal nutrition factors, the lying material source (wood chips, rice rusk, straw) and the litter management (reuse cycles and climate variations). Costa et al. (2012) found a methane production of $145 \pm 14 \mathrm{~L} \mathrm{~kg}^{-1}$ in samples from Portugal. Markou (2015) found variable BMP (50 to $150 \mathrm{~mL} \mathrm{~g}^{-1}$ ) in PL samples from Greece. In similar samples from Brazil, Vicente et al. (2018) found BBP of 179, 158, and $117 \mathrm{~L}$ per $\mathrm{kg}$ for dry mass PL samples with six, seven and eight bed reuse feedlots, respectively. Marchioro et al. (2018) found a BBP of $183 \mathrm{~L} \mathrm{kg-1}$ for sample of PL after 12 cycles of broiler production.

When compared to the results obtained after US pretreatment, assay 2 presented the highest biogas production compared to the others assays $\left(163.0 \mathrm{~mL} \mathrm{~g}^{-1}\right), 10.2 \%$ higher than crude PL. Assay 2 showed the highest TOC and TRS concentration and, as presented in the previous item, it can be inferred that the US energy enabled the increase of the accessibility of the structure by simplifying and increasing the surface area. These findings suggest that biogas production could be improved by increasing the availability of compounds to anaerobic microorganisms (Cesaro and Belgiorno, 2014).

The maximum biogas production rate $\left(r_{m}\right)$ was higher in the pre-treated samples than in the crude PL, mainly in assays 5 , 6, and 7 (> $\left.24.7 \mathrm{~mL} \mathrm{~d}^{-1}\right)$ using $60 \%$ of US amplitude and $15 \%$ of dry mass. The exception was assay 1, possibly the result of the low energy applied to the system $(126.33 \mathrm{~kJ}$ $\mathrm{L}^{-1}$ ), with consequent reduction of facilitated access to the hydrolysis step.

Increased biogas production and production velocity can be inferred from the greater release of easily accessible organic material after pre-treatment. The disintegration of PL particles, observed by SEM, can cause a deviation of the hydrolytic step and consequently greater biogas production. The same was observed in the study of Houtmeyers et al. (2014).

Methane percentage on samples pre-treated by US did not show significant changes in relation to crude PL, on average $63 \%$. These results have been observed in other studies, suggested that US promoted mechanisms that do not necessarily lead to the disintegration and solubilization of organic matter but cause changes in the structure of the organic substrate, possibly causing changes in the reaction rate and velocity of the hydrolysis step (Cesaro and Belgiorno, 2014; Houtmeyers et al., 2014).

US is efficient in reducing biomass particles size, facilitating the access of microorganisms in the degradation of easily assimilable compounds; however, some organic particulates require more aggressive pre-treatment for disruption and are relatively difficult to disrupt mechanically. The combination of chemical substances is also reported to improve lignocellulosic compounds exposure. Nevertheless, chemical additives are not selective and in case of PL, other organic compounds that are important for biogas production would also be degraded (Santos et al., 2018; Tian X. et al., 2018). Therefore, it was inferred from this study that the application of higher energy by increasing the exposure time to the US system 
TABLE 4 | BPP and kinetics parameters using Gompertz model for PL crude and pre-treated with US.

\begin{tabular}{|c|c|c|c|c|c|c|c|}
\hline Assay & $\begin{array}{c}\text { Amplitude } \\
\text { (\%) }\end{array}$ & $\begin{array}{c}\text { Dry } \\
\text { mass (\%) }\end{array}$ & $\begin{array}{c}A \\
\left(m L g^{-1}\right)\end{array}$ & $\begin{array}{c}r_{m} \\
\left(m L g^{-1}\right. \\
\left.d^{-1}\right)\end{array}$ & $\begin{array}{c}r_{m} \\
\text { day (d) }\end{array}$ & $\lambda(\mathrm{d})$ & $R^{2}(\%)$ \\
\hline Crude litter & - & - & 147.9 & 20.0 & 3.3 & 0.3 & 98.0 \\
\hline 1 & $-1(20)$ & $-1(10)$ & 155.3 & 14.9 & 3.5 & 0.0 & 96.4 \\
\hline 2 & $1(100)$ & $-1(10)$ & 163.0 & 20.9 & 2.9 & 0.0 & 97.6 \\
\hline 3 & $-1(20)$ & $1(20)$ & 146.7 & 22.2 & 2.8 & 0.6 & 99.3 \\
\hline 4 & $1(100)$ & $1(20)$ & 153.0 & 21.9 & 2.6 & 0.0 & 98.3 \\
\hline 5 & $0(60)$ & $0(15)$ & 134.1 & 24.7 & 2.4 & 0.0 & 99.1 \\
\hline 6 & $0(60)$ & $0(15)$ & 143.0 & 25.4 & 2.3 & 0.0 & 98.8 \\
\hline 7 & $0(60)$ & $0(15)$ & 140.3 & 24.7 & 2.3 & 0.0 & 98.2 \\
\hline
\end{tabular}

Where: $A=$ maximum $B P P, r_{m}=$ maximum biogas production rate, $r_{m}$ day $=$ day of occurrence of the maximum biogas production rate, $\lambda=$ lag phase and $R^{2}=$ determination coefficient.

could improve biogas production. The results were presented in Table 5, where the conditions employed on assays U1U4 and results for TOC and TRS have been previously reported (Table 3 ).

Experimental results of BBP were in agreement with theoretical values obtained using Gompertz model $\left(R^{2}\right.$, Table 5). TOC increased with the increase in US time (Table 3) however a result that was different from what was expected the application of larger amounts of energy decreased biogas production as demonstrated by results for biogas obtained on assays U1-U4 (Table 5). This may be related to the occurrence of mineralization phenomena due to the absence of US selectivity (Cesaro and Belgiorno, 2014).

In the PL, in addition to the lignocellulosic material from the wood shavings, there are animal feces that are more easily degradable than lignocellulosic fraction. It is possible that, although the increased US time allowed greater degradation of lignocellulosic material, more easily degraded organic compounds suffered complete degradation $\left(\mathrm{CO}_{2}\right.$ formation) and had volatilized. Cavitation in aqueous solutions causes homolytic cleavage of water molecules with the production of hydroxyl radicals $(\bullet \mathrm{OH})$, one of the most powerful known oxidants. On reaction with $\mathrm{HO} \bullet$, organic compounds rapidly convert into oxidized species that then further degrade into smaller molecules, or that fully degrade to $\mathrm{CO}_{2}$ and $\mathrm{H}_{2} \mathrm{O}$ (Bremner et al., 2011).

These findings suggest that, as the concentration of TOC increased with the increase of US time and energy applied (Table 3), it is possible that some of organic compounds were lost and other less biodegradable compounds that remained into solution did not contribute to the same extent for biogas production (Passos et al., 2014). Nominal values obtained for day of occurrence of the maximum velocity of biogas production $\left(\mathrm{r}_{\mathrm{m}}\right.$ d) could corroborate with these findings as values decreased with the increase of US energy applied indicating more degradation of lignocellulosic chains. Nevertheless, Tukey test evaluation showed that there was no statistical difference (95\% confidence level) among values obtained in different US assays. Values for velocity of biogas production $\left(\mathrm{r}_{\mathrm{m}}, \mathrm{mL} \mathrm{g}^{-1} \mathrm{~d}^{-1}\right)$ and $\lambda$ (related to duration of lag phase) were also considered statistically equivalent. These data suggest that the application of US during short periods or using controlled amounts of energy could enhance biogas production from PL (Bremner et al., 2011).

\section{Energy Recovery From PL: A Circular Economy Preview and Possible Pre-treatment Strategies Viability}

A simplified analysis to estimate the value addition on pretreated PL was calculated on basis of processing 1 ton of material. Parameters used in calculating the processing costs are based on the laboratory study with the following conditions: (a) $10 \mathrm{~m}^{3}$ of liquid effluent rich in TAN would be generated per $1,000 \mathrm{~kg}$ of PL after water washing process; (b) concentration of TAN on liquid extracted fraction is $400 \mathrm{mgN} \mathrm{L}^{-1}$, which corresponds to $4 \mathrm{~kg}$ on $\mathrm{N}$ per $1,000 \mathrm{~kg}$ of PL; (c) if applied additional membrane technology process for recovery high purity ammonia, the expected efficiency is $90 \%$ (Busato et al., 2020). In this process, ammonia is converted to $\left(\mathrm{NH}_{4}\right)_{2} \mathrm{SO}_{4}$. Thus, $17 \mathrm{~kg}$ of $\left(\mathrm{NH}_{4}\right)_{2} \mathrm{SO}_{4}$ could be produced/ton of $\mathrm{PL}$; d) finally, considering the price of $\left(\mathrm{NH}_{4}\right)_{2} \mathrm{SO}_{4}$ as US\$ 350/ton, the value of recovered $\left(\mathrm{NH}_{4}\right)_{2} \mathrm{SO}_{4}$ from one ton of PL is US\$5.95.

Furthermore, the biogas from PL can replace the use of firewood for thermal demand during the first days of bird's life, when the animal thermoregulatory system is not yet fully developed. Considering a standard aviary location of $100 \mathrm{~m} \times$ $12 \mathrm{~m}$ size, with the capacity to housing 14,500 broilers, it was estimated that this farm could produce $\sim 100,000 \mathrm{~kg}$ of PL after 12 cycles (Marchioro et al., 2018). According the BBP data from crude PL from Table 4, it is possible to produce $14,790 \mathrm{~m}^{3}$ of biogas. After US pre-treatment this potential could increase to $17,930 \mathrm{~m}^{3}$ of biogas.

Nevertheless, these projections scenarios are based in data from a laboratory evaluation process. It is important to emphasize that complementary full-scale validation are necessary.

\section{CONCLUSION}

Two different ways of pre-treating PL were evaluated, to value this residue in biotechnological processes of interest. It was found a low C:N ratio and the presence of TAN, both of which may complicate subsequent biological processes. TAN removal from PL by washing with water in a continuous and successive washing system was evaluated. I was found greater removal of TAN in the successive washing process (36\%), enabling the application of $\mathrm{PL}$ in TAN recovery processes for industrial use or as fertilizer, and enabling water recovery by reducing the water footprint of the process. It was also evaluated the action of US pretreatment on the lignocellulosic fraction of PL, obtaining a $10 \%$ increase in biogas production. Results of the AD of PL pre-treated with US showed a positive perspective to improve the biogas production, suggesting that the applied technique improves the process and can be tested for other purposes, aiming to add value by improving PL digestibility. The overall goal is to reduce the environmental impacts of direct disposal of the material in 
TABLE 5 | BPP, methane percentages and kinetics parameters of Gompertz model in samples with higher energy applied in PL pre-treatment by US.

\begin{tabular}{|c|c|c|c|c|c|c|c|}
\hline Assay & Biogas & Methane (\%) & $A\left(m L g^{-1}\right)$ & $\mathbf{r}_{\mathrm{m}}\left(\mathrm{mL} \mathbf{g}^{-1} \mathbf{d}^{-1}\right)$ & $\mathbf{r}_{\mathrm{m}}$ day $(\mathbf{d})$ & $\lambda(\mathrm{d})$ & $R^{2}(\%)$ \\
\hline U1 & $154.7 \pm 11.0$ & 56.6 & $153.4^{a} \pm 10.4$ & $21.6^{a} \pm 1.0$ & $4.1^{a} \pm 0.1$ & $1.4^{a} \pm 0.1$ & 99.9 \\
\hline U2 & $140.6 \pm 9.0$ & 55.3 & $139.9^{a, b} \pm 8.7$ & $20.0^{\mathrm{a}} \pm 1.5$ & $3.9^{a} \pm 0.1$ & $1.3^{a} \pm 0.1$ & 99.9 \\
\hline U3 & $150.5 \pm 7.0$ & 56.7 & $149.4^{\mathrm{a}, \mathrm{b}} \pm 8.3$ & $21.7^{a} \pm 1.1$ & $3.9^{a} \pm 0.2$ & $1.3^{a} \pm 0.1$ & 99.9 \\
\hline U4 & $126.0 \pm 11.0$ & 58.9 & $126.3^{b} \pm 11.4$ & $19.4^{a} \pm 1.6$ & $3.7^{a} \pm 0.1$ & $1.3^{a} \pm 0.1$ & 99.7 \\
\hline
\end{tabular}

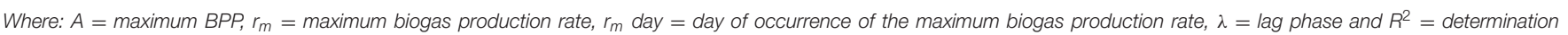
coefficient. Note: equal lowercase letters in same column do not differ statistically from each other by Tukey test (95\% confidence level).

the soil using sustainable techniques, without the addition of chemical compounds and with reduced effluent generation.

\section{DATA AVAILABILITY STATEMENT}

The datasets generated for this study are available on request to the corresponding author.

\section{AUTHOR CONTRIBUTIONS}

TG contributed in the accomplishment of the experiments, treatment and discussion of the data, and writing of the article. TS assisted with the execution of the experiments, treatment and discussion of the data, and writing of the article. BV assisted with the execution of the experiments and treatment and discussion of the data. DT contributed in the accomplishment of the experiments. ML assisted with the execution of the experiments. AV assisted with conducting the experiments. RF assisted with the execution of the experiments. AC assisted with the execution of the experiments. FA contributed in the accomplishment of

\section{REFERENCES}

Abouelenien, F., Kitamura, Y., Nishio, N., and Nakashimada, Y. (2009). Dry anaerobic ammonia-methane production from chicken manure. Appl. Microbiol. Biotechnol. 82, 757-764. doi: 10.1007/s00253-009-1881-3

ABPA (Brazilian Association of Animal Protein) (2018). Annual Report. Available online at: http://abpa-br.com.br/storage/files/relatorio-anual-2018 (accessed October 17, 2019).

APHA AWWA and WEF (2012). Standard Methods for the Examination of Water and Wastewater, 22nd Edn. Washington, DC: APHA002E.

Balaji, S., Sakthivel, M., Pasupathy, A. S., and Sivakumar, P. (2018). Mitigation of nitrogen in the poultry litter to enhance biomethane production. Thermal Sci. 22, 3083-3090. doi: 10.2298/TSCI161004113B

Biton, G. (2010). Wastewater Microbiology, 4 Edn. Hoboken, NJ: Wiley-Blackwell.

Böjti, T., Kovács, K. L., Kakuk, B., Wirth, R., Rákhely, G., and Bagi, Z. (2017). Pretreatment of poultry manure for efficient biogas production as monosubstrate or co-fermentation with maize silage and corn stover. Anaerobe 46, 138-145. doi: 10.1016/j.anaerobe.2017.03.017

Bondhoo, Z. M. A., and Mohee, R. (2018). Ultrasound-assisted biological conversion of biomass and waste materials to biofuels: a review. Ultrason. Sonochem. 40, 298-313. doi: 10.1016/j.ultsonch.2017.07.025

Bremner, D. H., Burgess, A. E., and Chand, R. (2011). The chemistry of ultrasonic degradation of organic compounds. Curr. Org. Chem. 15, 168-177. doi: 10.2174/138527211793979862

Burra, K. G., Hussein, M. S., Amano, R. S., and Gupta, A. K. (2016). Syngas evolutionary behavior during chicken manure pyrolysis and air gasification. Appl. Energy 181, 408-415. doi: 10.1016/j.apenergy.2016. 08.095 the experiments using US, treatment and discussion of the data, and writing of the article. RS contributed to the accomplishment of the experiments, treatment and discussion of the data and, writing of the article. HT assisted with the accomplishment of the experiments, treatment and discussion of the data, and writing of the article. AK also assisted in the execution of experiments, treatment and discussion of the data, and writing of the article.

\section{ACKNOWLEDGMENTS}

This study had financial support from Project EMBRAPA Nr. 20.18.03.012.00.02.002; CAPES, CNPq, FAPERGS, and FAPESC.

\section{SUPPLEMENTARY MATERIAL}

The Supplementary Material for this article can be found online at: https://www.frontiersin.org/articles/10.3389/fbioe. 2020.00477/full\#supplementary-material
Busato, C. J., Da Ros, C., Pellay, R., Barbierato, P., and Pavan, P. (2020) Anaerobic membrane reactor: biomethane from chicken manure and highquality effluent. Ren. Energy 145, 1647-1657. doi: 10.1016/j.renene.2019.07.088

Cavalaglio, G., Coccia, V., Cotana, F., Gelosia, M., Nicolini, A., and Petrozzi, A. (2018). Energy from poultry waste: an aspen Plus-based approach to the thermo-chemical processes. Waste Manage. 73, 496-503. doi: 10.1016/j.wasman.2017.05.037

Cesaro, A., and Belgiorno, V. (2014). Pretreatment methods to improve anaerobic biodegradability of organic municipal solid waste fractions. Chem. Eng. J. 240, 24-37. doi: 10.1016/j.cej.2013.11.055

Chaump, K., Preisser, M., Shanmugam, S. R., Prasad, R., Adhikari, S., and Higgins, B. T. (2019). Leaching and anaerobic digestion of poultry litter for biogas production and nutrient transformation. Waste Manag. 84, 413-422. doi: 10.1016/j.wasman.2018.11.024

Costa, J. C., Barbosa, S. G., Alves, M. M., and Souza, D. Z. (2012). Thermochemical pre- and biological co-treatments to improve hydrolysis and methane production from poultry litter. Biores. Technol. 111, 141-147. doi: 10.1016/j.biortech.2012.02.047

Den, W., Sharma, V. K., Lee, M., Nadadur, G., and Varma, R. (2018). Lignocellulosic biomass transformations via greener oxidative pretreatment processes: access to energy and value-added chemicals. Front. Chem. 6:141. doi: $10.3389 /$ fchem.2018.00141

DIN Deutsches Institut für Normung. (1985). DIN 384140-8. German Standard Method for the Examination of Water, Water and Sludge. Sludge and Sediment (Group S). Determination of Amenability to anaerobic digestion. (S8).

Félix, E. P., and Cardoso, A. A. (2004). Atmospheric ammonia: sources, transformation, sinks, and methods of analysis. Química Nova 27, 123-130. doi: 10.1590/S0100-40422004000100022 
Fernandes, T. V., Bos, G. J. K., Zeeman, G., Sanders, J. P. M., and Van Lier, J. B. (2009). Effects of thermo-chemical pre-treatment on anaerobic biodegradability and hydrolysis of lignocellulosic biomass. Bioresour. Technol. 100, 2575-2579. doi: 10.1016/j.biortech.2008. 12.012

Fuchs, W., Wang, X., Gabauer, W., Ortnerc, M., and Li, Z. (2018). Tackling ammonia inhibition for efficient biogas production from chicken manure: Status and technical trends in Europe and China. Renew. Sust. Energy Rev. 97, 186-199. doi: 10.1016/j.rser.2018.08.038

Garoma, T., and Pappaterra, D. (2018). An investigation of ultrasound effect on digestate solubilization and methane yield. Waste Manag. 71, 728-733. doi: 10.1016/j.wasman.2017.03.021

Holliger, C., Alves, M., Andrade, D., Angelidaki, I., Astals, S., Baier, U., et al. (2016). Towards standardization of biomethane potential tests. Water Sci. Technol. 74, 2515-2522. doi: 10.2166/wst.2016.336

Houtmeyers, S., Degrève, J., Willems, K., Dewil, R., and Appels, L. (2014). Comparing the influence of low power ultrasonic and microwave pre-treatments on the solubilisation and semi-continuous anaerobic digestion of waste activated sludge. Bioresour. Technol. 171, 44-49. doi: 10.1016/j.biortech.2014.08.029

Kunz, A., and Mukhtar, S. (2016). Hydrophobic membrane technology for ammonia extraction from wastewaters. Eng. Agric. 36, 377-386. doi: 10.1590/1809-4430-Eng.Agric.v36n2p377-386/2016

Langone, M., Soldano, M., Fabbri, C., Pirozzi, F., and Andreottola, G. (2018) Anaerobic digestion of cattle manure influenced by swirling jet induced hydrodynamic cavitation. Appl. Biochem. Biotechnol. 184, 1200-1218. doi: $10.1007 /$ s12010-017-2612-3

Lippert, T., Bandelin, J., Much, A., Drewes, J. E., and Koch, K. (2018). Energy-positive sewage sludge pre-treatment with a novel ultrasonic flatbed reactor at low energy input. Bioresour. Technol. 264, 298-305. doi: 10.1016/j.biortech.2018.05.073

Marchioro, V., Steinmetz, R. L. R., Amaral, A. C., Gaspareto, T. C., Treichel, H., and Kunz, A. (2018). Poultry litter solid state anaerobic digestion: effect of digestate recirculation intervals and substrate/inoculum ratios on process efficiency. Front. Sustain. Food Syst. 2:46. doi: 10.3389/fsufs.2018.00046

Markou, G. (2015). Improved anaerobic digestion performance and biogas production from poultry litter after lowering its nitrogen content. Bioresour. Technol. 196, 726-730. doi: 10.1016/j.biortech.2015.07.067

Mason, T. J., Cobley, A. J., Graves, J. E., and Morgan, D. (2011). New evidence for the inverse dependence of mechanical and chemical effects on the frequency of ultrasound. Ultrason. Sonochem. 18, 226-230. doi: 10.1016/j.ultsonch.2010.05.008

Matusiak, K., Oleksy, M., Borowski, S., Nowak, A., Korczynski, M., Dobrzanski, Z., et al. (2016). The use of Yucca schidigera and microbial preparation for poultry manure deodorization and hygienization. J. Environ. Manag. 170, 50-59. doi: 10.1016/j.jenvman.2016.01.007

Miller, G. L. (1959). The use of dinitrosalicylic acid reagent for the determination of reducing sugars. Anal. Chem. 31, 1321-1326. doi: 10.1021/ac60147a030

Passos, F., Astals, S., and Ferrer, I. (2014). Anaerobic digestion of microalgal biomass after ultrasound pretreatment. J. Waste Manag. 34, 2098-2103. doi: 10.1016/j.wasman.2014.06.004

Pérez-Elvira, S., Fdz-Polanco, M., Plaza, F. I., Garralón, G., and Fdz-Polanco, F. (2014). Ultrasound pre-treatment for anaerobic digestion improvement. Water Sci. Technol. 60, 1525-1532. doi: 10.2166/wst.2009.484

Rajagopal, R., Massé, D. I., and Sinh, G. (2013). A critical review on inhibition of anaerobic digestion process by excess ammonia. Bioresour. Technol. 143, 632-641. doi: 10.1016/j.biortech.2013.06.030

Rodrigues, M. I., and Iemma, A. F. (2014). Experimental Design and Process Optimization, 1st Edn. Boca Raton, FL: CRC Press.

Sakar, H., Celik, I., Balcik-Canbolat, C., Keskinler, B., and Karagunduz, A. (2019). Ammonium removal and recovery from real digestate wastewater by a modified operational method of membrane. J. Clean Prod. 215, 1415-1423. doi: 10.1016/j.jclepro.2019.01.165
Salehian, P., Karimi, K., Zilouei, H., and Jeihanipour, A. (2013). Improvement of biogas production from pine wood by alcali pretreatment. Fuel 106, 484-489. doi: 10.1016/j.fuel.2012.12.092

Santos, D., Silva, U. F., Duarte, F. A., Bizzi, C. A., Flores, E. M. M., and Mello, P. A. (2018). Ultrasound-assisted acid hydrolysis of cellulose to chemical building blocks: application to furfural synthesis. Ultrason. Sonochem. 40, 81-88. doi: 10.1016/j.ultsonch.2017.04.034

Selvaraj, B., Krishnasamy, S., Munirajan, S., Alagirisamy, P. S., Dhanushkodi, M., Gopalsamy, S., et al. (2018). Kinetic modelling of augmenting biomethane yield from poultry litter by mitigating ammonia. Int. J. Green Energy 15, 766-772. doi: 10.1080/15435075.2018.1529580

Shen, J., Wang, C., Liu, Y., Hu, C., Xin, Y., Ding, N. et al. (2018). Effect of ultrasonic pretreatment of the dairy manure on the electricity generation of microbial fuel cell. Biochem. Eng. J. 129, 44-49. doi: 10.1016/j.bej.2017.10.013

Shen, J., and Zhu, J. (2018). Kinetics of poultry litter in a leach bed reactor with agitation based on two mechanisms: enzymatic hydrolysis and direct solubilization. Biochem. Eng. J. 135, 115-122. doi: 10.1016/j.bej.2018.04.007

Steinmetz, R. L. R., Mezzari, M. P., Silva, M. L. B., Kunz, A., Amaral, A. C., Tápparo, D. C., et al. (2016). Enrichment and acclimation of an anaerobic mesophilic microorganism's inoculum for standardization of BMP assays. Bioresour. Technol. 219, 21-28. doi: 10.1016/j.biortech.2016.07.031

Tian, H., Fotidis, I. A., Kissas, K., and Agelidaki, I. (2018). Effect of different ammonia sources on acetoclastic and hydrogenotrophic methanogens. Bioresour. Technol. 250, 390-397. doi: 10.1016/j.biortech.2017.11.081

Tian, X., Ng, W. J., and Trzcinski, A. P. (2018). Optimizing the synergistic effect of sodium hydroxide/ultrasound pre-treatment of slugde. Ultrason. Sonochem. 48, 432-440. doi: 10.1016/j.ultsonch.2018.07.005

VDI 4630 (2016). Fermentation of Organic Materials: Characterization of the Substrate, Sampling, Collection of Material Data, Fermentation Tests. The Association of German Engineers, Düsseldorf.

Vicente D. J. Jr., Costa, M. S. S. M., Costa, L. A. M., Pereira, D. C., and Dos Santos, F. T. (2018). Anaerobic digestion and co-digestion of poultry litter submitted to different reuses. Eng. Agríc. 38, 961-967. doi: 10.1590/1809-4430-eng.agric.v38n6p961-967/2018

Ware, A., and Power, N. (2017). Modelling methane production kinetics of complex poultry slaughterhouse wastes using sigmoidal growth functions. Renew. Energy 104, 50-59. doi: 10.1016/j.renene.2016.11.045

Yun, S., Fang, W., Du, T., Hu, X., Huang, X., Li, X., et al. (2018). Use of bio-based carbon materials for improving biogas yield and digestate stability. Energy J. 164, 898-909. doi: 10.1016/j.energy.2018.09.067

Zahan, Z., and Othman, M. Z. (2019). Effect of pre-treatment on sequential anaerobic co-digestion of chicken litter with agricultural and food wastes under semi-solid conditions and comparison with wet anaerobic digestion. Bioresour. Technol. 281, 286-295. doi: 10.1016/j.biortech.2019.01.129

Zhang, C., Ma, J., and Waite, T. D. (2020). The impact of absorvents on ammonia recovery in a capacitive membrane stripping system. Chem. Eng. J. 382:122851. doi: 10.1016/j.cej.2019.122851

Zou, S., Wang, X., Chen, Y., Wan, H., and Feng, Y. (2016) Enhancement of biogas production in anaerobic co-digestion by ultrasonic pretreatment. Energy Convers. Manag. 112, 226-235. doi: 10.1016/j.enconman.2015.12.087

Conflict of Interest: The authors declare that the research was conducted in the absence of any commercial or financial relationships that could be construed as a potential conflict of interest.

Copyright (C) 2020 Gaspareto, Scapini, Venturin, Tápparo, Camargo, Luccio, Valerio, Favretto, Antes, Steinmetz, Treichel and Kunz. This is an open-access article distributed under the terms of the Creative Commons Attribution License (CC BY). The use, distribution or reproduction in other forums is permitted, provided the original author(s) and the copyright owner(s) are credited and that the original publication in this journal is cited, in accordance with accepted academic practice. No use, distribution or reproduction is permitted which does not comply with these terms. 